OPEN ACCESS

Edited by:

Gary John Loake,

University of Edinburgh, UK

Reviewed by:

Jinxing Lin

Beijing Forestry University, China

Chris Gehring,

King Abdullah University of Science

and Technology, Saudi Arabia

*Correspondence: Inonge Gross inonge.mulako@helmholtzmuenchen.de

Specialty section: This article was submitted to Plant Cell Biology,

a section of the journal

Frontiers in Plant Science

Received: 27 November 2015

Accepted: 14 April 2016

Published: 06 May 2016

Citation:

Gross I and Durner J (2016) In Search of Enzymes with a Role in 3', 5'-Cyclic Guanosine Monophosphate Metabolism in Plants.

Front. Plant Sci. 7:576. doi: 10.3389/fpls.2016.00576

\section{In Search of Enzymes with a Role in 3', 5'-Cyclic Guanosine Monophosphate Metabolism in Plants}

\author{
Inonge Gross ${ }^{1 *}$ and Jörg Durner ${ }^{1,2}$ \\ ${ }^{1}$ Nitric Oxide Production and Signalling Group, Institute of Biochemical Plant Pathology, Helmholtz Center Munich, Germany, \\ ${ }^{2}$ Chair of Biochemical Plant Pathology, Technische Universität München, Freising, Germany
}

In plants, nitric oxide (NO)-mediated 3', 5'-cyclic guanosine monophosphate (cGMP) synthesis plays an important role during pathogenic stress response, stomata closure upon osmotic stress, the development of adventitious roots and transcript regulation. The NO-cGMP dependent pathway is well characterized in mammals. The binding of $\mathrm{NO}$ to soluble guanylate cyclase enzymes (GCs) initiates the synthesis of cGMP from guanosine triphosphate. The produced cGMP alters various cellular responses, such as the function of protein kinase activity, cyclic nucleotide gated ion channels and cGMPregulated phosphodiesterases. The signal generated by the second messenger is terminated by 3', 5'-cyclic nucleotide phosphodiesterase (PDEs) enzymes that hydrolyze cGMP to a non-cyclic 5'-guanosine monophosphate. To date, no homologues of mammalian cGMP-synthesizing and degrading enzymes have been found in higher plants. In the last decade, six receptor proteins from Arabidopsis thaliana have been reported to have guanylate cyclase activity in vitro. Of the six receptors, one was shown to be a NO dependent guanylate cyclase enzyme (NOGC1). However, the role of these proteins in planta remains to be elucidated. Enzymes involved in the degradation of cGMP remain elusive, albeit, PDE activity has been detected in crude protein extracts from various plants. Additionally, several research groups have partially purified and characterized PDE enzymatic activity from crude protein extracts. In this review, we focus on presenting advances toward the identification of enzymes involved in the cGMP metabolism pathway in higher plants.

Keywords: nitric oxide, cGMP, phosphodiesterases, plants, guanylate cyclase, signaling

\section{INTRODUCTION}

The second messenger $3^{\prime}, 5^{\prime}$-cyclic guanosine monophosphate (cGMP) discovered in the 1960s is found in both prokaryotes and eukaryotes (Ashman et al., 1963; Eckstein, 1988; Müller, 1997; Cadoret et al., 2005). The molecule cGMP is synthesized from guanosine triphosphate (GTP) by guanylate cyclase enzymes (GCs) and is involved in various cellular responses, such as protein kinase activity, cyclic nucleotide gated ion channels and cGMP regulated cyclic nucleotide phosphodiesterases (Denninger and Marletta, 1999; Gomelsky and Galperin, 2013). The signal generated by the second messenger is halted by $3^{\prime}, 5^{\prime}-$ cyclic nucleotide phosphodiesterase (PDE) enzymes (Hoyer et al., 1994; Richter, 2002; Maurice et al., 2014). In mammals, the metabolism and physiological role of cGMP is 
well characterized, this cyclic nucleotide is important in olfactory signaling (Pietrobon et al., 2011), visual adaptation (Vielma et al., 2011) and vasodilation (Thoonen et al., 2013). In contrast, the role of cGMP in plants is not well understood.

Cyclic nucleotide monophosphates (cNMP) levels including cGMP are lower in plants relative to other eukaryotes and as a result the detection and quantification of cNMP was challenging for several decades (Newton and Smith, 2004). However, with the development of sensitive methods, it is now possible to measure and quantify cNMP in planta. The methods include; mass spectrometry based measurements (Newton and Smith, 2004), radiolabeled (Steiner et al., 1972) and antibody (Lomovatskaya et al., 2011) based immunoassays. In addition, non-invasive techniques have been developed that allow the detection of endogenous cytoplasmic cGMP levels in vivo, these include a fluorescent cGMP biosensor called FlincG (Isner and Maathuis, 2011) and a cGMP responsive promoter fused to a luciferase reporter gene (Wheeler et al., 2013). Consequently, in the past decade, several research groups have shown a positive correlation between the accumulation of cGMP in planta and various developmental processes as well as the response to abiotic and pathogenic stress (Figure 1; Durner et al., 1998; Pagnussat et al., 2003b; Szmidt-Jaworska et al., 2004; Maathuis, 2006; Suita et al.,
2009; Teng et al., 2010; Joudoi et al., 2013; Li et al., 2014; Nan et al., 2014). For instance, Durner et al. (1998) were the first group to show a correlation between nitric oxide (NO) dependent cGMP synthesis and pathogen defense response in Nicotiana tabacum. The elevated levels of cGMP in turn activated the expression of a pathogenic marker, phenylalanine ammonia lyase (PAL). In the subsequent years, several research groups have documented that both NO-dependent and NO-independent cGMP signaling pathways are important in the activation of defense responses during biotic stress (Klessig et al., 2000; Ma et al., 2007; Meier et al., 2009; Pasqualini et al., 2009; Qi et al., 2010; Ma et al., 2013). Additionally, NO-cGMP dependent signaling pathway has been reported to be involved in the development of adventitious roots (Pagnussat et al., 2003a,b; Xuan et al., 2012), stomata closure during abiotic and biotic stress (Neill et al., 2008; Joudoi et al., 2013), protein phosphorylation (Isner et al., 2012; Marondedze et al., 2015) and transcription regulation (Suita et al., 2009).

Collectively, research in the last two decades suggests that cGMP is an important second messenger in plants, albeit, the metabolism of cGMP in plants is not well understood. In this review, we focus on advances toward the identification of enzymes involved in the metabolism of cGMP in plants.

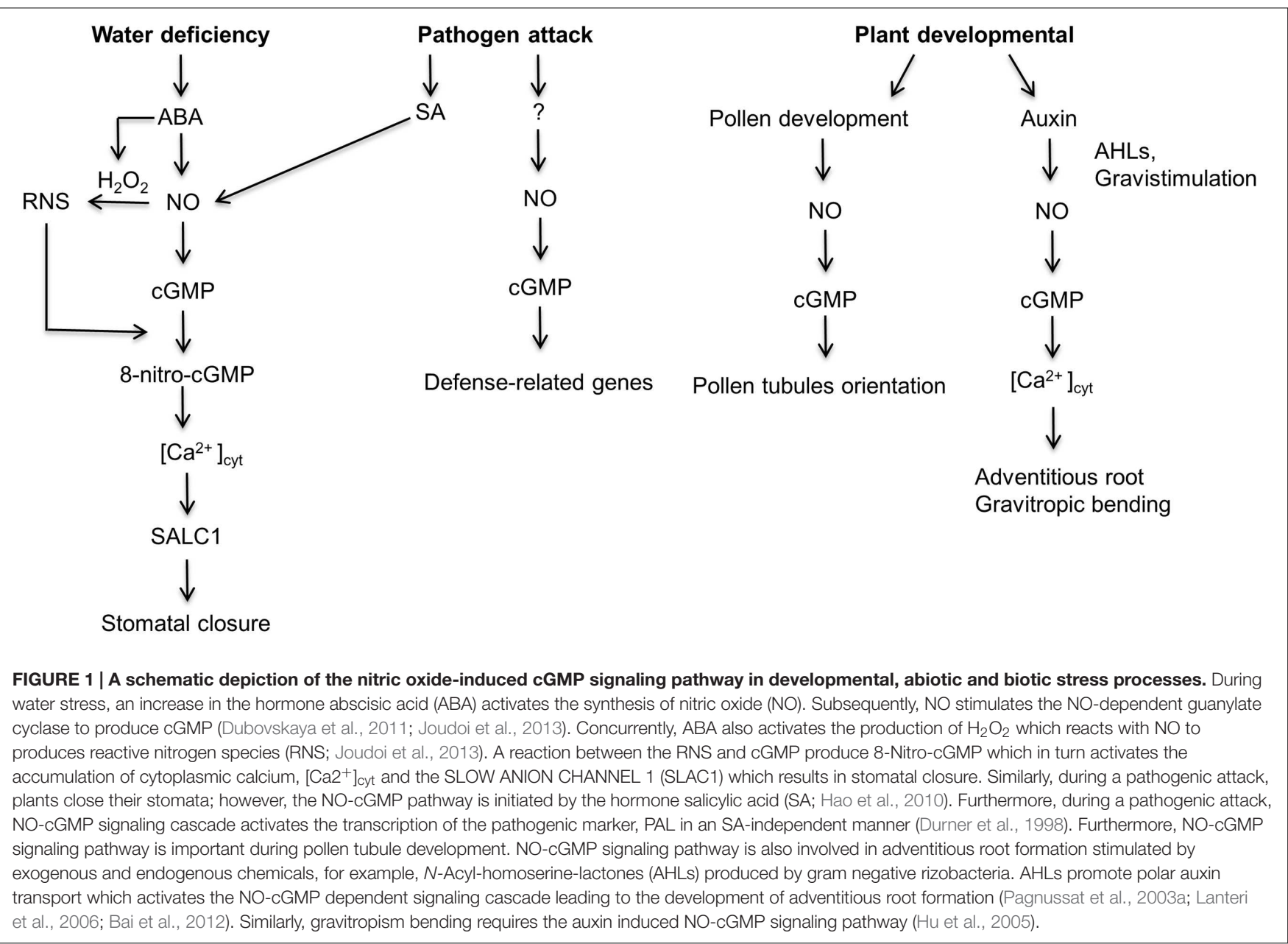




\section{NITRIC OXIDE DEPENDENT GUANYLATE CYCLASE ENZYMES IN PLANTS}

In the plant kingdom, genes coding for nucleotide cyclase (NCs) enzymes have been identified in lower plants from the division of Chlorophyta. For instance Chlamydomonas reinhardtii contains more than 90 NCs enzymes (Meier et al., 2007; Marondedze et al., 2016). Among these annotated NCs, NO-induced GC enzymes homologous to those found in mammalian species have been identified (Winger et al., 2008; de Montaigu et al., 2010). In higher plants, protein sequences with high homology to known GCs have not been identified. However, motif searches based on functionally assigned amino acid residues within the catalytic center has resulted in the identification of several proteins that have been shown to have guanylate cyclase activity in vitro. These include; phytosulfokine (PSK) receptor, AtPepR1, Arabidopsis thaliana guanylate cyclase 1 (AtGC1), brassinosteroid receptor (AtBRII), plant natriuretic peptide receptor (AtPNP-R1) and wall associated kinase-like 10 (AtWAKL10: Ludidi and Gehring, 2003; Kwezi et al., 2007; Meier et al., 2010; Qi et al., 2010; Kwezi et al., 2011; Turek and Gehring, 2016). These receptors synthesize cGMP from GTP independent of NO.

In an effort to identify NO-dependent GCs in plants, Mulaudzi et al. (2011) searched the Arabidopsis thaliana sequence database for the conserved residues within the catalytic center as well as the heme-nitric oxide and oxygen binding domain ( $\mathrm{H}$ NOX), a domain required for the binding of NO in GCs. The authors found one protein annotated as a Flavin-dependent monooxygenase (Atlg62580) that contained both the H-NOX motif and the conserved amino acid residues within the catalytic motif. The enzyme was termed NO dependent guanylate cyclase 1 (NOGC1). Interestingly, stomata closure did not occur in nogc1 T-DNA knockout mutants lines when treated with an NO donor, 1-hydroxy-2-oxo-3-(3-aminopropyl)-3-isopropyl-1triazene, compared to wild type plants (NOC5; Joudoi et al., 2013). These exciting results suggest that NOGC1 is involved in the NO-cGMP signaling pathway in regard to stomatal closure. Furthermore, in vitro assays confirmed that the recombinant protein NOGC1 has a higher affinity for NO than oxygen (Mulaudzi et al., 2011). However, although NOGC1 recombinant protein is able to synthesize cGMP in an NO dependent manner, cGMP is produced in extremely low amounts (400-450 fmol/ $\mu \mathrm{g}$ in $20 \mathrm{~min}$ ) relative to GCs found in mammals, for example the recombinant sGC from human $(940 \mathrm{pmol} / \mathrm{min} / \mu \mathrm{g}$; Kosarikov et al., 2001). It could be possible that additional unknown cofactors are required for the optimal function of this enzyme and therefore, the assay conditions in vitro are not ideal. Indeed this is true for the phytosulfokine receptor 1 (PSKR1) which showed an increase in GC activity in the presence of calcium (Muleya et al., 2014). Furthermore, there are additional factors that affect the production of active recombinant proteins; these are discussed in detail by Bernaudat et al. (2011) and references therein. As suggested by Wong and Gehring (2013), it is important that further studies are carried out in vivo. For example, the synthesis of cGMP by NOGC1 could be studied in plants containing the cGMP biosensor FlincG (Isner and Maathuis, 2011). The advantage of this system is that the detection of cGMP is noninvasive; therefore, continuous real-time changes in cGMP could be studied. A further advantage is that cytosolic cGMP levels can be detected in specific organelles, thus, allowing high resolution measurements.

In contrast to the recent developments in the identification of NO induced GCs in plants, the publications concerning the identification of plant specific $3^{\prime}, 5^{\prime}$-cyclic nucleotide phosphodiesterase enzymes (PDEs) responsible for the degradation of cGMP stopped in 2001. It is peculiar that there has been no research output in regard to the identification of PDEs from plants in the last 16 years. The next section provides a summary on the efforts in the identification of PDEs and the comparison of their physical and chemical properties to the PDEs found in prokaryotes, lower and higher eukaryotes.

\section{$3^{\prime}, 5^{\prime}$-CYCLIC UANOSINE MONOPHOSPHATE PHOSPHODIESTERASES FOUND IN PROKARYOTIC AND EUKARYOTIC ORGANISMS}

3', 5'-cyclic nucleotide phosphodiesterase enzymes (PDEs) degrade cGMP and the other second messenger, $3^{\prime}, 5^{\prime}$-cyclic adenosine monophosphate (cAMP). The PDE superfamily is classified into three groups (Class I, Class II, and Class III) based on sequence and structural similarities (Figure 2). Class I PDEs are found in higher and lower eukaryotic organisms including all mammalian species and numerous species belonging to the Amoebozoa and Fungi kingdoms (Sass et al., 1986; Michaeli et al., 1993; Rosman et al., 1997; Thomason et al., 1998; Fawcett et al., 2000; Fujishige et al., 2000; Hetman et al., 2000; Kuwayama et al., 2001; Wang et al., 2001; Lee et al., 2002; Richter, 2002; Huai et al., 2003; Jung and Stateva, 2003; Wang et al., 2003; Zhang et al., 2005; Bader et al., 2006; Corbin et al., 2006; Muradov et al., 2010; DeNinno et al., 2011; Barnes, 2013; Zhu et al., 2013; Du et al., 2014; Maurice et al., 2014). Class II PDEs are found in lower eukaryotes and bacteria (Van Haastert et al., 1983; Van Haastert and Van Lookeren Campagne, 1984; Lacombe et al., 1986; Dunlap and Callahan, 1993; Hoyer et al., 1994; Imamura et al., 1996; Degerman et al., 1997; Bosgraaf et al., 2002; Bader et al., 2007; Tian et al., 2014). Finally, members of class III belong exclusively to PDEs isolated from prokaryotes (Imamura et al., 1996; Richter, 2002; Shenoy et al., 2005; Zheng et al., 2013). Although Class I, II, and III PDEs have different sequence and structure homology, they use similar mechanisms in the hydrolysis of cNMP by cleaving the ester bond at carbon $3^{\prime}$ to produce a non-cyclic $5^{\prime}$ NMP. These enzymes belong to a superfamily called binuclear metallohydrolases (Mitić et al., 2006).

\section{Partially Purified PDEs from Plants with Promiscuous Enzyme Activity}

In the plant kingdom, lower plants from the division of Chlorophyta contain genes coding for classic Class I PDEs within their genome. As shown by our phylogenetic tree analysis, 


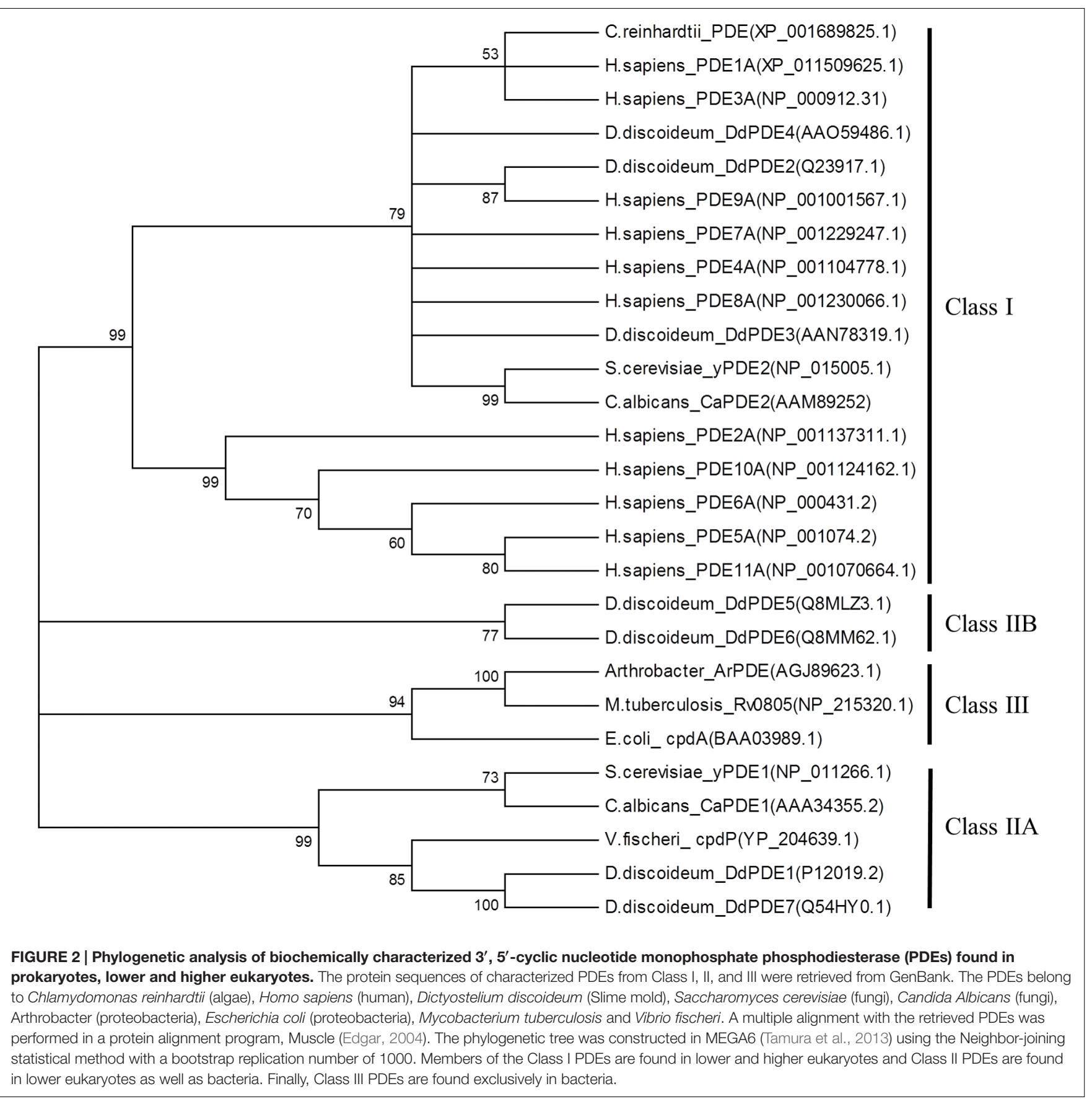

a PDE from Chlamydomonas reinhardtii is closely related to mammalian Class I PDE 1A and 3A (Figure 2). These findings complement studies by Fischer and Amrhein (1974) who showed that a partially purified protein from C. reinhardtii exhibited typical Class I enzyme activity during the hydrolysis of cAMP and cGMP. This enzyme was also able to hydrolyze $3^{\prime}, 5^{\prime}$ cyclic cytosine monophosphate (cCMP) and the hydrolysis was threefold and sixfold higher than cAMP and cGMP, respectively. These findings are compatible with recent data that shows that mammalian PDEs exhibit promiscuous substrate specificity toward other $3^{\prime}, 5^{\prime}$-cyclic nucleotides than previously reported, for example, cyclic uridine monophosphate (cUMP), cyclic thymidine monophosphate (cTMP) and cyclic inosine monophosphate (cIMP; Reinecke et al., 2011).

In higher plants such as angiosperms, PDEs have not been identified; however, PDE activity has been detected in crude protein extracts from various plants. In an effort to purify PDEs, crude extract from Solanum tuberosum (Ashton and Polya, 1975; Zan-Kowalczewsk et al., 1984), Pisum sativum (Lin and Varner, 1972), Nicotiana tabacum (Shinshi et al., 1976; Matsuzaki and Hashimoto, 1981) and Solanum lycopersicum (Abel et al., 2000) were subjected to sequential purification steps that 
included ammonium sulfate precipitation, ion chromatography and gel filtration chromatography. Molecular weights of protein fractions with PDE activity were determined by gel filtration with markers of known molecular weight. Proteins capable of hydrolyzing cNMP were present as monomeric as well as tetrameric protein complexes. The molecular weight values for the monomer and tetramer PDEs range from 60 000-75 000 and $270000-350000$, respectively and they all possess similar enzymatic activity properties. In other plants, the partially purified PDEs appear in fractions at lower molecular weights than the proposed size of the monomeric form, $60000-75$ 000. In Spinacea oleracea, the sizes of partially purified PDEs with estimated sizes of 50 and $37 \mathrm{KDa}$ were reported (Brown et al., 1979). All partially purified PDEs mentioned were from crude cytosolic (soluble) proteins. However, Vandepeute et al. (1973) report the partial purification of PDE from both soluble proteins and particulate (membrane) proteins, suggesting that plants could possess both cytosolic and membrane bound PDEs.

In contrast to Class I, II, and III PDEs, all mentioned PDEs above hydrolyze $2^{\prime}, 3^{\prime}$ and $3^{\prime}, 5^{\prime}$-cNMPs with most of them showing a higher affinity toward the hydrolysis of $2^{\prime}, 3^{\prime} \mathrm{cNMP}$ than $3^{\prime}, 5^{\prime}$-cNMP (Supplementary Table S1; Lin and Varner, 1972; Ashton and Polya, 1975; Brown et al., 1979; Endress, 1979; Abel et al., 2000). It is probable that unlike other organisms, plants contain PDEs with dual enzymatic function. This claim is supported by the finding from a partially purified PDE $(70 \mathrm{kDa})$ from S. lycopersicum that was shown to be induced and excreted from suspension-cultured cells during inorganic phosphate deficiency (Abel et al., 2000). It was proposed that together with ribonuclease I and acid phosphatases, plant PDEs are expressed and secreted to degrade extracellular RNA, releasing inorganic phosphate that is in turn transported into the cells via Pi transporters. The authors speculate that due to its higher affinity for $2^{\prime}, 3^{\prime}$ cNMPs than $3^{\prime}, 5^{\prime}$-cNMPs and because it is excreted during phosphate deficiency, the PDE identified is involved in RNA turnover rather than the degradation of $3^{\prime}$, 5-cNMP and thus the enzyme was named 2', $3^{\prime}$-cyclic nucleotidephosphodiesterase. An alternative suggestion is that in plants, PDEs and nucleotide pyrophosphates are part of a multi-complex structure and because they possess similar properties such as isoelectric point and molecular weight, they co-purify during the isolation process. This is a more convincing theory as other groups have reported partially purified PDEs that specifically degrade $3^{\prime}, 5^{\prime}$-cNMP isomers; these are discussed in the following section.

\section{Partial Purification of 3', 5'-Cyclic Nucleotide Monophosphate Specific PDEs in Plants}

To isolate protein with PDE activity from Phaseolus vulgaris, the authors extracted total soluble extract from the vegetative tissue and centrifuged it at $100000 \mathrm{~g}$ (Brown et al., 1977). The pellet was retained and dissolved in $50 \mathrm{mM}$ Tris-HCL buffer (pH7.4) and the following purification steps were performed; ammonium sulfate precipitation and gel filtration (Sephadex G-200). Two fractions containing PDE activity were detected with molecular weights of 340 and $76 \mathrm{KDa}$, confirming that in plants PDEs could exist in monomeric and tetrameric forms. In addition, both enzyme fractions produced a mixture of $3^{\prime} \mathrm{NMP}$ and $5^{\prime}$ NMP after the hydrolysis of $3^{\prime}, 5^{\prime}$-cNMPs, similar to all partially purified plant PDEs described to date. Interestingly, PDE from $P$. vulgaris was described to specifically hydrolyze $3^{\prime}, 5^{\prime}$-cNMP and had no activity against $2^{\prime}, 3$-cAMP. The substrate preference is in the following order: $3^{\prime}, 5^{\prime}$-cAMP, $3^{\prime}, 5^{\prime}$-cGMP, $3^{\prime}, 5^{\prime}$-cUMP and $3^{\prime}, 5^{\prime}$-cCMP (Brown et al., 1977). Similarly, partially purified PDE from S. oleracea and P. volganic were reported to have catalytic preference for $3^{\prime}, 5^{\prime}$-cNMP (Brown et al., 1980; Diffley et al., 2001). The PDE from S. oleracea hydrolyzed both $3^{\prime}, 5^{\prime}$ cAMP and $3^{\prime}, 5^{\prime}$-cAMP and divalent metals were not required for optimal enzyme activity. The hydrolysis of $3^{\prime}, 5^{\prime}$-cAMP and $3^{\prime}, 5^{\prime}$-cAMP by the partially purified PDE from $P$. volganic was activated and inhibited by $\mathrm{Mg}^{2+/} \mathrm{Mn}^{2+}$ and $\mathrm{Fe}^{3+}$, respectively. These results indicate that the PDE from $P$. volganic requires divalent metals similar to CLASS I PDEs found in eukaryotic organisms. However, in contrast to CLASS I PDEs, the presence of $\mathrm{Fe}^{3+}$ activated the hydrolysis of $3^{\prime}, 5^{\prime}$-cCMP (Diffley et al., 2001).

\section{The Future for Plant Specific PDE Research}

It is possible to speculate that with the advances in proteomics in the last 16 years, there is a high chance that plant-specific PDEs could be identified from the sequentially fractionated samples. For example, the refined liquid chromatography coupled mass spectrometry (LC MS/MS) based proteomics analysis techniques are now capable of deciphering protein mixtures. The sensitivity of the techniques allows the identification of proteins in low abundance (Ahlf et al., 2013; Di Girolamo et al., 2013; Fukao et al., 2013). Furthermore, peptides fingerprints/proteins from the mass spectrometry analysis can be readily identified as the genomes of 49 plants species have been sequenced since 2001 (Michael and Jackson, 2013). These include the genomes of S. tuberosum (Xu et al., 2011), N. tabacum (Sierro et al., 2014), and S. lycopersicum (Daniell et al., 2006).

\section{CONCLUSION}

Nitric oxide-dependent cGMP production is involved in various signaling processes in plants particularly in (i) the control of stomatal aperture which is important in surviving water deficit (Neill et al., 2008; Joudoi et al., 2013) and (ii) defense response during pathogen attack (Durner et al., 1998; Ma et al., 2013). NOGC1 is the first NO-dependent GC identified in plants; however, the function of this protein remains to be elucidated in planta. As stated, the last publication on identifying plant specific PDEs was in 2001. Finding plant PDEs could have a substantial impact in understanding the NO-cGMP pathway and its physiological effects. As cGMP is positively correlated with plants adapting to environmental stresses, the discovery of PDEs will lead to the development of plant-specific PDE 
inhibitors which would maintain intracellular levels of cGMP. In mammals, perturbation in the synthesis as well as degradation of cGMP results in various human ailments (Maurice et al., 2014). Inhibitors of mammalian PDEs are used as therapeutic agents to regulate the concentrations of intracellular cGMP and thus alleviate diseases. It is safe to postulate that plant specific PDE inhibitors could be important in improving crop performance during environmental stress and thus could have similar commercial value as the well-studied mammalian PDEs.

\section{REFERENCES}

Abel, S., Nürnberger, T., Ahnert, V., Krauss, G. J., and Glund, K. (2000). Induction of an extracellular cyclic nucleotide phosphodiesterase as an accessory ribonucleolytic activity during phosphate starvation of cultured tomato cells. Plant. Physiol. 122, 543-552. doi: 10.1104/pp.122.2.543

Ahlf, D. R., Thomas, P. M., and Kelleher, N. L. (2013). Developing top down proteomics to maximize proteome and sequence coverage from cells and tissues. Curr. Opin. Chem. Biol. 17, 787-794. doi: 10.1016/j.cbpa.2013. 07.028

Ashman, D. F., Lipton, R., Melicow, M. M., and Price, T. D. (1963). Isolation of adenosine $3^{\prime}, 5^{\prime}$-monophosphate and guanosine $3^{\prime}, 5^{\prime}$-monophosphate from rat urine. Biochem. Biophys. Res. Commun. 11, 330-334. doi: 10.1016/0006291X(63)90566-7

Ashton, A. R., and Polya, G. M. (1975). Higher-plant cyclic nucleotide phosphodiesterases. Resolution, partial purification and properties of three phosphodiesterases from potato tuber. Biochem. J. 149, 329-339. doi: 10.1042/bj1490329

Bader, S., Kortholt, A., Snippe, H., and Van Haastert, P. J. (2006). DdPDE4, a novel cAMP-specific phosphodiesterase at the surface of dictyostelium cells. J. Biol. Chem. 281, 20018-20026. doi: 10.1074/jbc.M600040200

Bader, S., Kortholt, A., and Van Haastert, P. J. (2007). Seven Dictyostelium discoideum phosphodiesterases degrade three pools of cAMP and cGMP. Biochem. J. 402, 153-161. doi: 10.1042/BJ20061153

Bai, X., Todd, C. D., Desikan, R., Yang, Y., and Hu, X. (2012). N-3-oxo-decanoylL-homoserine-lactone activates auxin-induced adventitious root formation via hydrogen peroxide- and nitric oxide-dependent cyclic GMP signaling in mung bean. Plant Physiol. 158, 725-736. doi: 10.1104/pp.111.185769

Barnes, P. J. (2013). Theophylline. Am. J. Respir. Crit. Care Med. 188, 901-906. doi: 10.1164/rccm.201302-0388PP

Bernaudat, F., Frelet-Barrand, A., Pochon, N., Dementin, S., Hivin, P., Boutigny, S., et al. (2011). Heterologous expression of membrane proteins: choosing the appropriate host. PLoS. ONE 6:e29191. doi: 10.1371/journal.pone.00 29191

Bosgraaf, L., Russcher, H., Snippe, H., Bader, S., Wind, J., and Van Haastert, P. J. (2002). Identification and characterization of two unusual cGMPstimulated phoshodiesterases in dictyostelium. Mol. Biol. Cell 13, 3878-3889. doi: 10.1091/mbc.E02-05-0302

Brown, E. G., Al-Najafi, T., and Newton, R. P. (1977). Cylcic nucleotide phosphodiesterase activity in Phaseolus Vulgaris. Phytochemistry 16, 13331337. doi: 10.1016/S0031-9422(00)88777-4

Brown, E. G., Edwards, M. J., Newton, R. P., and Smith, C. J. (1979). Plurality of cyclic nucleotide phosphodiesterase in spinacea oleracea: subcellular distribution, partial purification, and properties. Phytochemistry 18, 1943-1948. doi: 10.1016/S0031-9422(00)82708-9

Brown, E. G., Edwards, M. J., Newton, R. P., and Smith, C. J. (1980). The cyclic nucleotide phosphodiesterases of spinach chloroplasts and microsomes. Phytochemistry 19, 23-30. doi: 10.1016/0031-9422(80) 85007-2

Cadoret, J. C., Rousseau, B., Perewoska, I., Sicora, C., Cheregi, O., Vass, I., et al. (2005). Cyclic nucleotides, the photosynthetic apparatus and response to a UVB stress in the Cyanobacterium Synechocystis sp. PCC 6803. J. Biol. Chem. 280, 33935-33944.

\section{AUTHOR CONTRBUTIIONS}

The first and corresponding author, IG initiated and wrote the review. JD proof-read the manuscript and gave intellectual input.

\section{SUPPLEMENTARY MATERIAL}

The Supplementary Material for this article can be found online at: http://journal.frontiersin.org/article/10.3389/fpls.2016.00576

Corbin, J., Francis, S., and Zoraghi, R. (2006). Tyrosine-612 in PDE5 contributes to higher affinity for vardenafil over sildenafil. Int. J. Impot Res. 18, 251-257. doi: 10.1038/sj.ijir.3901411

Daniell, H., Lee, S. B., Grevich, J., Saski, C., Quesada-Vargas, T., Guda, C., et al. (2006). Complete chloroplast genome sequences of Solanum bulbocastanum, Solanum lycopersicum and comparative analyses with other Solanaceae genomes. Theor. Appl. Genet. 112, 1503-1518. doi: 10.1007/s00122-0060254-x

de Montaigu, A., Sanz-Luque, E., Galván, A., and Fernández, E. (2010). A soluble guanylate cyclase mediates negative signaling by ammonium on expression of nitrate reductase in Chlamydomonas. Plant. Cell 22, 1532-4158. doi: $10.1105 /$ tpc. 108.062380

Degerman, E., Belfrage, P., and Manganiello, V. C. (1997). Structure, localization, and regulation of cGMP-inhibited phosphodiesterase (PDE3). J. Biol. Chem. 272, 6823-6826. doi: 10.1074/jbc.272.11.6823

DeNinno, M. P., Wright, S. W., Visser, M. S., Etienne, J. B., Moore, D. E., Olson, T. V., et al. (2011). 1,5-Substituted nipecotic amides: selective PDE8 inhibitors displaying diastereomer-dependent microsomal stability. Bioorg. Med. Chem. Lett. 21, 3095-3098. doi: 10.1016/j.bmcl.2011.03.022

Denninger, J. W., and Marletta, M. A. (1999). Guanylate cyclase and the NO/cGMP signaling pathway. Biochim. Biophys. Acta 1411, 334-350. doi: 10.1016/S00052728(99)00024-9

Di Girolamo, F., Lante, I., Muraca, M., and Putignani, L. (2013). The role of mass spectrometry in the "omics". Era. Curr. Org. Chem. 17, 2891-2905. doi: $10.2174 / 1385272817888131118162725$

Diffley, P. E., Geisbrecht, A., Newton, R. P., Oliver, M., Smith, C. J., Vaughan, J., et al. (2001). Variation in isomeric products of a phosphodiesterase from the chloroplasts of Phaseolus vulgaris in response to cations. Plant. Biosystems. 135, 143-156. doi: 10.1080/11263500112331350760

Du, Q., Schilde, C., Birgersson, E., Chen, Z. H., McElroy, S., and Schaap, P. (2014). Structural basis for the activity of drugs that inhibit phosphodiesterases. The cyclic AMP phosphodiesterase RegA critically regulates encystation in social and pathogenic amoebas. Cell Signal 26, 453-459. doi: 10.1016/j.cellsig.2013.10.008

Dubovskaya, L. V., Bakakina, Y. S., Kolesneva, E. V., Sodel, D. L., McAinsh, M. R., Hetherington, A. M., et al. (2011). cGMP-dependent ABA-induced stomatal closure in the ABA-insensitive Arabidopsis mutant abil-1. New Phytol. 191, 57-69. doi: 10.1111/j.1469-8137.2011.03661.x

Dunlap, P. V., and Callahan, S. M. (1993). Characterization of a periplasmic $3^{\prime}: 5^{\prime}-$ cyclic nucleotide phosphodiesterase gene, cpdp, from the marine symbiotic bacterium Vibrio fischeri. J. Bacteriol. 175, 4615-4624.

Durner, J., Wendehenne, D., and Klessig, D. F. (1998). Defense gene induction in tobacco by nitric oxide, cyclic GMP, and cyclic ADP-ribose. Proc. Natl. Acad. Sci. U.S.A. 95, 10328-10333. doi: 10.1073/pnas.95.17.10328

Eckstein, H. (1988). $3^{\prime}: 5^{\prime}$-cyclic GMP in the yeast Saccharomyces cerevisiae at different metabolic conditions. FEBS Lett. 232, 121-124. doi: 10.1016/00145793(88)80399-5

Edgar, R. C. (2004). MUSCLE: multiple sequence alignment with high accuracy and high throughput. Nucleic Acids Res. 32, 1792-1797. doi: 10.1093/nar/ gkh340

Endress, R. (1979). Allosteric regulation of phosphodiesterase from Portulaca callus by cGMP and papaverin. Phytochemistry 18, 15-20. doi: 10.1016/S00319422(00)90905-1 
Fawcett, L., Baxendale, R., Stacey, P., McGrouther, C., Harrow, I., Soderling, S., et al. (2000). Molecular cloning and characterization of a distinct human phosphodiesterase gene family: PDE11A. Proc. Natl. Acad. Sci. U.S.A. 97, 3702-3707. doi: 10.1073/pnas.97.7.3702

Fischer, U., and Amrhein, N. (1974). Cyclic nucleotide phosphodiesterase of Chlamydomonas Reinhardii. Biochim. Biophys. Acta 341, 412-420. doi: 10.1016/0005-2744(74)90234-4

Fujishige, K., Kotera, J., Yuasa, K., and Omori, K. (2000). The human phosphodiesterase PDE10A gene genomic organization and evolutionary relatedness with other PDEs containing GAF domains. Eur. J. Biochem. 267, 5943-5951. doi: 10.1046/j.1432-1327.2000.01661.x

Fukao, Y., Yoshida, M., Kurata, R., Kobayashi, M., Nakanishi, M., Fujiwara, M., et al. (2013). Peptide separation methodologies for in-depth proteomics in Arabidopsis. Plant Cell Physiol. 54, 808-815. doi: 10.1093/pcp/pct033

Gomelsky, M., and Galperin, M. Y. (2013). Bacterial second messengers, cGMP and c-di-GMP, in a quest for regulatory dominance. EMBO. J. 32, 2421-2423. doi: 10.1038/emboj.2013.193

Hao, F., Zhao, S., Dong, H., Zhang, H., Sun, L., and Miao, C. (2010). Nial and $\mathrm{Nia} 2$ are involved in exogenous salicylic acid-induced nitric oxide generation and stomatal closure in Arabidopsis. J. Integr. Plant Biol. 52, 298-307. doi: 10.1111/j.1744-7909.2010.00920.x

Hetman, J. M., Robas, N., Baxendale, R., Fidock, M., Phillips, S. C., Soderling, S. H., et al. (2000). Cloning and characterization of two splice variants of human phosphodiesterase 11A. Proc. Natl. Acad. Sci. U.S.A. 97, 12891-12895. doi: 10.1073/pnas.200355397

Hoyer, L. L., Cieslinski, L. B., McLaughlin, M. M., Torphy, T. J., Shatzman, A. R., and Livi, G. P. (1994). A Candida albicans cyclic nucleotide phosphodiesterase: cloning and expression in Saccharomyces cerevisiae and biochemical characterization of the recombinant enzyme. Microbiology 140, 1533-1542. doi: 10.1099/13500872-140-7-1533

Hu, X., Neill, S. J., Tang, Z., and Cai, W. (2005). Nitric oxide mediates gravitropic bending in soybean roots. Plant Physiol. 137, 663-670. doi: 10.1104/pp.104.054494

Huai, Q., Colicelli, J., and Ke, H. (2003). The crystal structure of AMP-bound PDE4 suggests a mechanism for phosphodiesterase catalysis. Biochemistry 42, 13220-13226. doi: 10.1021/bi034653e

Imamura, R., Yamanaka, K., Ogura, T., Hiraga, S., Fujita, N., Ishihama, A., et al. (1996). Identification of the cpdA gene encoding cyclic $3^{\prime}, 5^{\prime}$-adenosine monophosphate phosphodiesterase in Escherichia coli. J. Biol. Chem. 271, 25423-25429. doi: 10.1074/jbc.271.41.25423

Isner, J. C., and Maathuis, F. J. (2011). Measurement of cellular cGMP in plant cells and tissues using the endogenous fluorescent reporter FlincG. Plant. J. 65, 329-334. doi: 10.1111/j.1365-313X.2010.04418.x

Isner, J. C., Nühse, T., and Maathuis, F. J. (2012). The cyclic nucleotide cGMP is involved in plant hormone signalling and alters phosphorylation of Arabidopsis thaliana root proteins. J. Exp. Bot. 63, 3199-3205. doi: 10.1093/jxb/ ers045

Joudoi, T., Shichiri, Y., Kamizono, N., Akaike, T., Sawa, T., Yoshitake, J., et al. (2013). Nitrated cyclic GMP modulates guard cell signaling in Arabidopsis. Plant. Cell. 25, 558-571. doi: 10.1105/tpc.112.105049

Jung, W. H., and Stateva, L. (2003). The cAMP phosphodiesterase encoded by CaPDE2 is required for hyphal development in Candida albicans. Microbiology 149, 2961-2976. doi: 10.1099/mic.0.26517-0

Klessig, D. F., Durner, J., Noad, R., Navarre, D. A., Wendehenne, D., Kumar, D., et al. (2000). Nitric oxide and salicylic acid signaling in plant defense. Proc. Natl. Acad. Sci. U.S.A. 97, 8849-8855. doi: 10.1073/pnas.97. 16.8849

Kosarikov, D. N., Young, P., Uversky, V. N., and Gerber, N. C. (2001). Human soluble guanylate cyclase: functional expression, purification and structural characterization. Arch. Biochem. Biophys. 388, 185-197. doi: 10.1006/abbi.2001.2284

Kuwayama, H., Snippe, H., Derks, M., Roelofs, J., and Van Haastert, P. J. (2001). Identification and characterization of DdPDE3, a cGMP-selective phosphodiesterase from Dictyostelium. Biochem. J. 353, 635-644. doi: 10.1042/0264-6021:3530635

Kwezi, L., Meier, S., Mungur, L., Ruzvidzo, O., Irving, H., and Gehring, C. (2007). The Arabidopsis thaliana brassinosteroid receptor (AtBRI1) contains a domain that functions as a guanylyl cyclase in vitro. PLoS. ONE 2:e449. doi: 10.1371/journal.pone.0000449

Kwezi, L., Ruzvidzo, O., Wheeler, J. I., Govender, K., Iacuone, S., Thompson, P. E., et al. (2011). The phytosulfokine (PSK) receptor is capable of guanylate cyclase activity and enabling cyclic GMP-dependent signaling in plants. J. Biol. Chem. 286, 22580-22588. doi: 10.1074/jbc.M110

Lacombe, M. L., Podgorski, G. J., Franke, J., and Kessin, R. H. (1986). Molecular cloning and developmental expression of the cyclic nucleotide phosphodiesterase gene of Dictyostelium discoideum. J. Biol. Chem. 261, 16811-16817.

Lanteri, M. L., Pagnussat, G. C., and Lamattina, L. (2006). Calcium and calciumdependent protein kinases are involved in nitric oxide- and auxin-induced adventitious root formation in cucumber. J. Exp. Bot. 57, 1341-1351. doi: 10.1093/jxb/erj109

Lee, M. E., Markowitz, J., Lee, J. O., and Lee, H. (2002). Crystal structure of phosphodiesterase 4D and inhibitor complex (1). FEBS Lett. 530, 53-58. doi: 10.1016/S0014-5793(02)03396-3

Li, J., Jia, H., and Wang, J. (2014). cGMP and ethylene are involved in maintaining ion homeostasis under salt stress in Arabidopsis roots. Plant Cell Rep. 33, 447-459. doi: 10.1007/s00299-013-1545-8

Lin, P. P.-C., and Varner, J. E. (1972). Cyclic nucleotide phosphodiesterases in pea seedlings. Biochim. Biophys. Acta 276, 454-474. doi: 10.1016/00052744(72)91007-8

Lomovatskaya, L., Romanenko, A., Filinova, N., and Dudareva, L. (2011). Determination of cAMP in plant cells by modified enzyme immune assay method. Plant Cell. Rep. 30, 125-132. doi: 10.1007/s00299-190950-5

Ludidi, N., and Gehring, C. (2003). Identification of a novel protein with guanylyl cyclase activity in Arabidopsis thaliana. J. Biol. Chem. 278, 6490-6494. doi: 10.1074/jbc.M210983200

Ma, W., Yoshioka, K., and Berkowitz, G. A. (2007). Cyclic nucleotide gated channels and ca-mediated signal transduction during plant innate immune response to pathogens. Plant Signal. Behav. 2, 548-550. doi: 10.4161/psb.2.6.4803

Ma, Y., Zhao, Y., Walker, R. K., and Berkowitz, G. A. (2013). Molecular steps in the immune signaling pathway evoked by plant elicitor peptides: $\mathrm{Ca}^{2+}$ dependent protein kinases, nitric oxide, and reactive oxygen species are downstream from the early $\mathrm{Ca}^{2+}$ signal. Plant. Physiol. 163, 1459-1471. doi: 10.1104/pp.113.226068

Maathuis, F. J. (2006). cGMP modulates gene transcription and cation transport in Arabidopsis roots. Plant. J. 45, 700-711. doi: 10.1111/j.1365-313X.2005.02616.x

Marondedze, C., Groen, A. J., Thomas, L., Lilley, K. S., and Gehring, C. (2015). A Quantitative phosphoproteome analysis of cGMP-dependent cellular responses in Arabidopsis thaliana. Mol. Plant 9, 621-623. doi: 10.1016/j.molp.2015.11.007

Marondedze, C., Wong, A., Thomas, L., Irving, H., and Gehring, C. (2016). Cyclic Nucleotide Monophosphates in Plants and Plant Signaling. Handb. Exp. Pharmacol. doi: 10.1007/164_2015_35 [Epub ahead of print].

Matsuzaki, H., and Hashimoto, Y. (1981). Purification and characterization of acid phosphodiesterases of cultured tobacco cells. Agric. Biol. Chem. 45, 1317-1325. doi: 10.1080/00021369.1981.10864711

Maurice, D. H., Ke, H., Ahmad, F., Wang, Y., Chung, J., and Manganiello, V. C. (2014). Advances in targeting cyclic nucleotide phosphodiesterases. Nat. Rev. Drug. Discov. 13, 290-314. doi: 10.1038/nrd4228

Meier, S., Madeo, L., Ederli, L., Donaldson, L., Pasqualini, S., and Gehring, C. (2009). Deciphering cGMP signatures and cGMP-dependent pathways in plant defence. Plant. Signal Behav. 4, 307-309. doi: 10.4161/psb.4. 4.8066

Meier, S., Ruzvidzo, O., Morse, M., Donaldson, L., Kwezi, L., and Gehring, C. (2010). The Arabidopsis wall associated kinase-like 10 gene encodes a functional guanylyl cyclase and is co-expressed with pathogen defense related genes. PLoS ONE 5:e8904. doi: 10.1371/journal.pone.0008904

Meier, S., Seoighe, C., Kwezi, L., Irving, H., and Gehring, G. (2007). Plant nucleotide cyclases. Plant Signal Behav. 2, 536-539. doi: 10.4161/psb.2. 6.4788

Michael, T. P., and Jackson, S. (2013). The First 50 Plant Genomes. Plant Genome 2, 1-7. doi: 10.3835/plantgenome2013.03.0001in 
Michaeli, T., Bloom, T. J., Martins, T., Loughney, K., Ferguson, K., Riggs, M., et al. (1993). Isolation and characterization of a previously undetected human cAMP phosphodiesterase by complementation of cAMP phosphodiesterase-deficient Saccharomyces cerevisiae. J. Biol. Chem. 268, 12925-12932.

Mitić, N., Smith, S. J., Neves, A., Guddat, L. W., Gahan, L. R., and Schenk, G. (2006). The catalytic mechanisms of binuclear metallohydrolases. Chem. Rev. 106, 3338-3363. doi: 10.1021/cr050318f

Mulaudzi, T., Ludidi, N., Ruzvidzo, O., Morse, M., Hendricks, N., Iwuoha, E., et al. (2011). Identification of a novel Arabidopsis thaliana nitric oxide-binding molecule with guanylate cyclase activity in vitro. FEBS Lett. 585, 2693-2697. doi: 10.1016/j.febslet.2011.07.023

Muleya, V., Wheeler, J. I., Ruzvidzo, O., Freihat, L., Manallack, D. T., Gehring, C., et al. (2014). Calcium is the switch in the moonlighting dual function of the ligand-activated receptor kinase phytosulfokine receptor 1. Cell Commun. Signal. 12:60. doi: 10.1186/s12964-014-0060-z

Müller, U. (1997). The nitric oxide system in insects. Prog. Neurobiol. 51, 363-438. doi: 10.1016/S0301-0082(96)00067-6

Muradov, H., Boyd, K. K., and Artemyev, N. O. (2010). Rod phosphodiesterase-6 PDE6A and PDE6B subunits are enzymatically equivalent. J. Biol. Chem. 285, 39828-39834. doi: 10.1074/jbc.M110.170068

Nan, W., Wang, X., Yang, L., Hu, Y., Wie, Y., Liang, X., et al. (2014). Cyclic GMP is involved in auxin signalling during Arabidopsis root growth and development. J. Exp. Bot. 65, 1571-1583. doi: 10.1093/jxb/eru019

Neill, S., Barros, R., Bright, J., Desikan, R., Hancock, J., Harrison, J., et al. (2008). Nitric oxide, stomatal closure, and abiotic stress. J. Exp. Bot. 59, 165-176. doi: 10.1093/jxb/erm 293

Newton, R. P., and Smith, C. J. (2004). Cyclic nucleotides. Phytochemistry 65, 2423-2437. doi: 10.1016/j.phytochem.2004.07.026

Pagnussat, G. C., Lanteri, M. L., and Lamattina, L. (2003a). Nitric oxide and cyclic GMP are messengers in the indole acetic acid-induced adventitious rooting process. Plant Physiol. 132, 1241-1248. doi: 10.1104/pp.103. 022228

Pagnussat, G. C., Lanteri, M. L., Lombardo, M. C., and Lamattina, L. (2003b). Nitric oxide mediates the indole acetic acid induction activation of a mitogenactivated protein kinase cascade involved in adventitious root development. Plant Physiol. 135, 279-286. doi: 10.1104/pp.103.038554

Pasqualini, S., Meier, S., Gehring, C., Madeo, L., Fornaciari, M., Romano, B., et al. (2009). Ozone and nitric oxide induce cGMP-dependent and -independent transcription of defence genes in tobacco. New Phytol. 181, 860-870. doi: 10.1111/j.1469-8137.2008.02711.x

Pietrobon, M., Zamparo, I., Maritan, M., Franchi, S. A., Pozzan, T., and Lodovichi, C. (2011). Interplay among cGMP, cAMP, and Ca2 in living olfactory sensory neurons in vitro and in vivo. J. Neurosci. 31, 8395-8405. doi: 10.1523/JNEUROSCI.6722-10.2011

Qi, Z., Verma, R., Gehring, C., Yamaguchi, Y., Zhao, Y., Ryan, C. A., et al. (2010). $\mathrm{Ca}^{2+}$ signaling by plant Arabidopsis thaliana Pep peptides depends on AtPepR1, a receptor with guanylyl cyclase activity, and cGMPactivated $\mathrm{Ca}^{2+}$ channels. Proc. Natl. Acad. Sci. U.S.A. 107, 21193-21198. doi: $10.1073 /$ pnas. 1000191107

Reinecke, D., Burhenne, H., Sandner, P., Kaever, V., and Seifert, R. (2011). Human cyclic nucleotide phosphodiesterases possess a much broader substratespecificity than previously appreciated. FEBS Lett. 585, 3259-3262. doi: 10.1016/j.febslet.2011.09.004

Richter, W. (2002). 3', $5^{\prime}$-Cyclic nucleotide phosphodiesterases class III: members, structure, and catalytic mechanism. Proteins 46, 278-286. doi: 10.1002/prot.10049

Rosman, G. J., Martins, T. J., Sonnenburg, W. K., Beavo, J. A., Ferguson, K., and Loughney, K. (1997). Isolation and characterization of human cDNAs encoding a cGMP-stimulated $3^{\prime}, 5^{\prime}$-cyclic nucleotide phosphodiesterase. Gene 191, 89-95. doi: 10.1016/S0378-1119(97)00046-2

Sass, P., Field, J., Nikawa, J., Toda, T., and Wigler, M. (1986). Cloning and characterization of the high-affinity cAMP phosphodiesterase of Saccharomyces cerevisiae. Proc. Natl. Acad. Sci. U.S.A. 83, 9303-9307. doi: 10.1073/pnas.83.24.9303

Shenoy, A. R., Sreenath, N., Podobnik, M., Kovacevic, M., and Visweswariah, S. S. (2005). The Rv0805 gene from Mycobacterium tuberculosis encodes a $3^{\prime}, 5^{\prime}$-cyclic nucleotide phosphodiesterase: biochemical and mutational analysis. Biochemistry 44, 15695-15704. doi: 10.1021/bi0512391
Shinshi, H., Miwa, M., Kato, K., Noguchi, M., Matsushima, T., and Sugimura, T. (1976). A novel phosphodiesterase from cultured tobacco cells. Biochemistry 15, 2185-2190. doi: 10.1021/bi00655a024

Sierro, N., Battey, J. N., Ouadi, S., Bakaher, N., Bovet, L., Willig, A., et al. (2014). The tobacco genome sequence and its comparison with those of tomato and potato. Nat. Commun. 5:3833. doi: 10.1038/ncomm s4833

Steiner, A. L., Wehmann, R. E., Parker, C. W., and Kipnis, D. M. (1972). Radioimmunoassay for the measurement of cyclic nucleotides. Adv. Cyclic. Nucleotide. Res. 2, 51-61.

Suita, K., Kiryu, T., Sawada, M., Mitsui, M., Nakagawa, M., Kanamaru, K., et al. (2009). Cyclic GMP acts as a common regulator for the transcriptional activation of the flavonoid biosynthetic pathway in soybean. Planta 229, 403413. doi: 10.1007/s00425-008-0839-5

Szmidt-Jaworska, A., Jaworski, K., Tretyn, A., and Kopcewicz, J. (2004). The involvement of cyclic GMP in the photoperiodic flower induction of Pharbitis nil. J. Plant. Physiol. 161, 277-284. doi: 10.1078/0176-161701122

Tamura, K., Stecher, G., Peterson, D., Filipski, A., and Kumar, S. (2013). MEGA6: molecular evolutionary genetics analysis version 6.0. Mol. Biol. Evol. 30, 27252729. doi: 10.1093/molbev/mst197

Teng, Y., Xu, W., and Ma, M. (2010). cGMP is required for seed germination in Arabidopsis thaliana. J. Plant. Physiol. 167, 885-889. doi: 10.1016/j.jplph.2010.01.015

Thomason, P. A., Traynor, D., Cavet, G., Chang, W. T., Harwood, A. J., and Kay, R. R. (1998). An intersection of the cAMP/PKA and two-component signal transduction systems in Dictyostelium. EMBO J. 17, 2838-2845. doi: 10.1093/emboj/17.10.2838

Thoonen, R., Sips, P. Y., Bloch, K. D., and Buys, E. S. (2013). Pathophysiology of Hypertension in the Absence of Nitric Oxide/Cyclic GMP. Signal. Curr. Hypertens. Rep. 15, 47-58. doi: 10.1007/s11906-012-0320-5

Tian, Y., Cui, W., Huang, M., Robinson, H., Wan, Y., Wang, Y., et al. (2014). Dual Specificity and novel structural folding of yeast phosphodiesterase1 for hydrolysis of second messengers cyclic adenosine and guanosine 3',5'-monophosphate. Biochemistry 53, 4938-4945. doi: 10.1021/bi5 $00406 \mathrm{~h}$

Turek, I., and Gehring, C. (2016). The plant natriuretic peptide receptor is a guanylyl cyclase and enables cGMP-dependent signaling. Plant Mol. Biol. doi: 10.1007/s11103-016-0465-8 [Epub ahead of print].

Van Haastert, P. J., Dijkgraaf, P. A., Konijn, T. M., Abbad, E. G., Petridis, G., and Jastorff, B. (1983). Substrate specificity of cyclic nucleotide phosphodiesterase from beef heart and from Dictyostelium discoideum. Eur. J. Biochem. 131, 659-666. doi: 10.1111/j.1432-1033.1983.tb07314.x

Van Haastert, P. J., and Van Lookeren Campagne, M. M. (1984). Transient kinetics of a cGMP-dependent cGMP-specific phosphodiesterase from Dictyostelium discoideum. J. Cell. Biol. 98, 709-716. doi: 10.1083/jcb.98.2.709

Vandepeute, J., Huffaker, R. C., and Alvarez, R. (1973). Cyclic nucleotide phosphodiesterase activity in barley seeds. Plant Physiol. 52, 278-282. doi: 10.1104/pp.52.3.278

Vielma, A. H., Retamal, M. A., and Schmachtenberg, O. (2011). Nitric oxide signaling in the retina: what have we learned in two decades? Brain Res. 1430, 112-125. doi: 10.1016/j.brainres.2011.10.045

Wang, P., Wu, P., Egan, R. W., and Billah, M. M. (2003). Identification and characterization of a new human type 9 cGMP-specific phosphodiesterase splice variant (PDE9A5). Differential tissue distribution and subcellular localization of PDE9A variants. Gene 314, 15-27. doi: 10.1016/S0378-1119(03)0 0733-9

Wang, P., Wu, P., Myers, J. G., Stamford, A., Egan, R. W., and Billah, M. M. (2001). Characterization of human, dog and rabbit corpus cavernosum type 5 phosphodiesterases. Life Sci. 68, 1977-1987. doi: 10.1016/S00243205(01)00989-4

Wheeler, J. I., Freihat, L., and Irving, H. R. (2013). A cyclic nucleotide sensitive promoter reporter system suitable for bacteria and plant cells. BMC Biotechnol. 13:97. doi: 10.1186/1472-6750-13-97

Winger, J. A., Derbyshire, E. R., Lamers, M. H., Marletta, M. A., and Kuriyan, J. (2008). The crystal structure of the catalytic domain of a eukaryotic guanylate cyclase. BMC Struct. Biol. 8:e57644. doi: 10.1186/1472-68 $07-8-42$ 
Wong, A., and Gehring, C. (2013). The Arabidopsis thaliana proteome harbors undiscovered multi-domain molecules with functional guanylyl cyclase catalytic centers. Cell Commun. Signal 11:48. doi: 10.1186/1478-811X-11-48

Xu, X., Pan, S., Cheng, S., Zhang, B., Mu, D., Ni, P., et al. (2011). Genome sequence and analysis of the tuber crop potato. Nature 475, 189-195. doi: 10.1038 /nature 10158

Xuan, W., Xu, S., Li, M., Han, B., Zhang, B., Zhang, J., et al. (2012). Nitric oxide is involved in hemin-induced cucumber adventitious rooting process. J. Plant. Physiol. 169, 1032-1039. doi: 10.1016/j.jplph.2012.02.021

Zan-Kowalczewsk, M., Bartkiewicz, M., Sierakowska, H., and Shugar, D. (1984). Purification and resolution of potato tuber cyclic nucleotide phosphodiesterase from nucleotide pyrophosphatase. Biochim. Biophys. Acta 788, 62-73. doi: 10.1016/0167-4838(84)90298-X

Zhang, X., Feng, Q., and Cote, R. H. (2005). Efficacy and selectivity of phosphodiesterase-targeted drugs in inhibiting photoreceptor phosphodiesterase (PDE6) in retinal photoreceptors. Invest. Ophthalmol. Vis. Sci. 46, 3060-3066. doi: 10.1167/iovs.05-0257

Zheng, Z., Zhu, M., He, Y., Li, N., Guo, T., Chen, Y., et al. (2013). Gene cloning, exprtession and characterization of a cyclic nucleotide phosphodiesterase from
Arthrobacter sp. CGMCC 3584. Appl. Biochem. Biotechnol. 169, 2442-2456. doi: 10.1007/s12010-013-0136-Z

Zhu, J., Yang, Q., Dai, D., and Huang, Q. (2013). X-ray crystal structure of phosphodiesterase 2 in complex with a highly selective, nanomolar inhibitor reveals a binding-induced pocket important for selectivity. J. Am. Chem. Soc. 135, 11708-11711. doi: 10.1021/ ja404449g

Conflict of Interest Statement: The authors declare that the research was conducted in the absence of any commercial or financial relationships that could be construed as a potential conflict of interest.

Copyright (c) 2016 Gross and Durner. This is an open-access article distributed under the terms of the Creative Commons Attribution License (CC BY). The use, distribution or reproduction in other forums is permitted, provided the original author(s) or licensor are credited and that the original publication in this journal is cited, in accordance with accepted academic practice. No use, distribution or reproduction is permitted which does not comply with these terms. 